\title{
Occupational risk factors for idiopathic pulmonary fibrosis in Southern Europe: a case-control study
}

\author{
Giulia Paolocci', Ilenia Folletti ${ }^{1}$, Kjell Torén², Magnus Ekström², Marco Dell'Omo', Giacomo Muzi ${ }^{1}$ \\ and Nicola Murgia ${ }^{1,2^{*}}$ (D)
}

\begin{abstract}
Background: Idiopathic pulmonary fibrosis (IPF) is a chronic, progressive fibrosing interstitial pneumonia of unknown cause associated with the histopathologic and/or radiologic pattern of usual interstitial pneumonia (UIP). Occupational risk factors have been proposed to be associated with UIP. The aim of this case-control study is to evaluate the relationship between UIP pattern and occupational exposure in Southern Europe.

Methods: Sixty nine cases with a UIP radiological pattern at CT-scan were selected from a clinical database of the University Hospital of Perugia, Umbria, between January 2010 and December 2013. Controls $(n=277)$ not reporting doctor diagnosed pulmonary fibrosis, were ascertained casually among general population from the same catching area of cases. Data were collected by a questionnaire used previously in a similar study. Logistic regression models, adjusted for gender, age and smoking, were performed to evaluate the association between UIP and occupational exposure.

Results: Farmers, veterinarians and gardeners $(\mathrm{OR}=2.73,95 \% \mathrm{Cl}=1.47-5.10)$, metallurgical and steel industry workers $(\mathrm{OR}=4.80,95 \% \mathrm{Cl}=1.50-15.33)$ were occupations associated with UIP. Metal dust and fumes and organic dust were risk factors for UIP. Increasing the length of occupational exposure in jobs at risk of pulmonary fibrosis, increased the risk of having UIP.

Conclusions: This case control study confirm partially the results from previous similar studies. Some discrepancies could be explained by the different geographical origins of the population under study, reflecting also different occupational exposures.
\end{abstract}

Keywords: Occupational, Workers, UIP, Pulmonary fibrosis

\section{Background}

Idiopathic pulmonary fibrosis (IPF) is a chronic, progressive, fibrosing interstitial lung disease of unknown cause with a high risk of rapid progression and mortality, the median survival after diagnosis is approximately 2 years [1].

The diagnosis of IPF requires exclusion of other known causes of idiophatic lung diseases, the presence of a usual interstitial pneumonia (UIP) pattern on high resolution CT-scan (HRCT) in patients not subjected to

\footnotetext{
* Correspondence: nicola.murgia@unipg.it

'Section of Occupational Medicine, Respiratory Diseases and Toxicology, University of Perugia, Piazzale Gambuli, 06100 Perugia, Italy

2Department of Occupational and Environmental Medicine, Sahlgrenska

University Hospital, Göteborg, Sweden
}

surgical lung biopsy (SLB) and specific combinations of HRCT and SLB patterns in patients subjected to SLB [2].

While several key cellular and molecular events have been identified in the pathogenesis of IPF, such as ageassociated telomerase dysfunction [3], incidence of IPF has increased in the last years with regional differences suggesting the pathogenic role of various environmental and occupational exposures [4].

Mechanisms governing the relationship between smoking, gender, occupational exposure and the development of severe pulmonary fibrosis are unknown but likely involve complex interactions between different environmental factors in genetically predisposed individuals [5].

(c) The Author(s). 2018 Open Access This article is distributed under the terms of the Creative Commons Attribution 4.0 International License (http://creativecommons.org/licenses/by/4.0/), which permits unrestricted use, distribution, and reproduction in any medium, provided you give appropriate credit to the original author(s) and the source, provide a link to the Creative Commons license, and indicate if changes were made. The Creative Commons Public Domain Dedication waiver (http://creativecommons.org/publicdomain/zero/1.0/) applies to the data made available in this article, unless otherwise stated. 
In similar studies made in America [6], Northern Europe [7] and Japan [8] occupational risk factors, including metal, stone and wood dust have been linked to higher risk of developing pulmonary fibrosis, but to date, the consistency of epidemiological evidence is suggestive but not sufficient to infer a causal relationship between several environmental exposure and IPF.

The aim of this study is to evaluate the relationship between UIP pattern and occupational exposure in Southern Europe.

\section{Methods}

The design was a case-control study of the adult population in Perugia, Umbria, Central Italy. 69 consecutive cases were included from the Perugia University Hospital clinical database between January 2010 and December 2013 and a random sample of 308 controls was selected among inhabitants of the same catchment area (Region Umbria). The diagnosis of UIP was based on clinical history, UIP pattern at CT scan and, when available, on open lung biopsy. All cases were consecutively included. Exclusion criteria were: laboratory testing compatible with autoimmune diseases, lung irradiation (radiotherapy), current or previous intake of medication known to cause lung fibrosis, compensation for occupational lung diseases resembling clinically and radiologically UIP (e.g asbestosis). Furthermore, cases with high suspicion, based on medical records and exposure history, of an occupational disease, even if not-compensated, were excluded.

All this information were gathered through the UIP patients medical records available at the Section of Occupational Medicine, Respiratory Diseases and Toxicology of the University Hospital of Perugia. The study protocol was approved by the Regional Ethical Committee (CEAS UMBRIA) and all the participants gave their informed verbal consent to the study. Due to the specific design of the study (telephone questionnaire), the informed consent was verbal. To approve the study, the ethical committee (CEAS UMBRIA) required the presence of a witness during questionnaire administration.

\section{Questionnaire and definitions}

Data were collected through an extensive telephonic questionnaire with items about occupations, duration of this occupations, specific self-reported occupational exposure, smoking habits and diagnosis of pulmonary fibrosis with information on atopy, rhinitis, family autoimmunity and family history of pulmonary fibrosis. The questionnaire has been described in detail elsewhere [7]. The response rate was 100\% among cases and 90\% among controls. Thus, the final number of controls enrolled in the study was 277.

Occupational exposure was ascertained by the answers to the self-reported questions. Self-reported exposures were lumped in 5 larger categories, metal dust and fumes, mineral dust, organic dust, vapour gas and nonmetal fumes, environmental tobacco smoke. To be classified as exposed, a subject had to report an occupation or an exposure lasting for at least 5 years and for cases, starting 5 years or more before the diagnosis of IPF, based on UIP pattern at CT scan.

Another measure of exposure was based on self-reported occupations: job titles were grouped into 12 job categories and of these, 5 have been considered at risk to cause UIP. The selection of the 5 job categories at risk to develop UIP was made through a review of the literature (Additional file 1). The search was conducted in the PubMed electronic database using the following search phrase: "Idiopathic pulmonary fibrosis" or "usual interstitial pneumonia" AND (occupation* OR work* OR environment) considering only review articles, in English language and human studies. Therefore, of 68 studies, 11 were selected and based on these 11 review articles, construction, wood, metallurgical and steel and chemical workers, as well as farmers, veterinarians (vets) and gardeners were considered professions at risk to generate the disease.

\section{Statistical analysis}

Significance of differences in prevalence were calculated by Chi-square test, and Fisher's exact test, when appropriate. Significance of differences in means were calculated using t-test. To evaluate different risk factors, logistic regression models have been built for occupation at risk of UIP and for self-reported exposure to occupational hazards, adjusting for gender, age, and smoking (ever and never). Specific models stratifying for gender and adjusting for age and smoking were also build. Associations were expressed as OR with $95 \% \mathrm{CI}$, statistical significance was defined as a double-sided $p<0.05$. Only exposure categories with five or more exposed cases were considered in the final analysis. Statistical analyses were performed using SPSS statistical software, version 20.0 (SPSS, IBM Corporation, New York, NY, USA).

\section{Results}

The study comprises 69 consecutive patients with UIP radiological pattern and 277 controls. The mean age was 75 years for cases and 71 for controls, $72.5 \%$ of cases and $54.2 \%$ of controls were males. Cases and controls had the same smoking exposure. No differences were found in distribution of family history pulmonary fibrosis as well as in atopy and rhinitis history between the two groups. Baseline characteristics are shown in Table 1.

Subjects with any occupational exposure to agents known to cause UIP had an increased risk for UIP (OR 4.1 95\% CI 2.3-7.55) (Table 2). 
Table 1 Characteristics of the population

\begin{tabular}{|c|c|c|c|}
\hline & UIP cases $(n=69)$ & Controls $(n=277)$ & $\mathrm{p}$ \\
\hline Males, n (\%) & $50(72.5)$ & $150(54.2)$ & $<0.01$ \\
\hline Age, mean $\pm S D$ & $75( \pm 14)$ & $71( \pm 13)$ & 0.02 \\
\hline \multicolumn{4}{|l|}{ Smoking } \\
\hline No smokers & $27(39.1)$ & $110(39.7)$ & \multirow[t]{2}{*}{ NS } \\
\hline Eversmokers & $42(60.9)$ & $167(60.3)$ & \\
\hline Atopy, n (\%) & $5(7.2)$ & $25(9.0)$ & NS \\
\hline Rhinitis, n (\%) & $22(31.9)$ & $75(27.1)$ & NS \\
\hline Family history of pulmonary fibrosis, n (\%) & $3(4.5)$ & $3(1.1)$ & 0.09 \\
\hline Family autoimmunity, n (\%) & $7(10.1)$ & $33(11.9)$ & NS \\
\hline Work duration (years), mean \pm SD & $38.6( \pm 10.6)$ & $35.4( \pm 10.5)$ & 0.02 \\
\hline \multicolumn{4}{|l|}{ Job title } \\
\hline Legislators, entrepreneurs, scientific and intellectual professions & $4(5.8)$ & $21(7.6)$ & NS \\
\hline Technical, social and health professions & $9(13)$ & $62(22.4)$ & NS \\
\hline Office workers & $11(15.9)$ & $48(17.3)$ & NS \\
\hline Dealers and service workers & $11(15.9)$ & $63(22.7)$ & NS \\
\hline Drivers or operatives of vehicles and installations & $6(8.7)$ & $42(15.2)$ & NS \\
\hline Construction workers & $14(20.3)$ & $26(9.4)$ & 0.02 \\
\hline Food industry workers & $5(7.2)$ & $30(10.8)$ & NS \\
\hline Textile industry workers & $9(13)$ & $36(13)$ & NS \\
\hline Wood industry workers & $6(8.7)$ & $15(5.4)$ & NS \\
\hline Metallurgical and steel industry & $8(11.6)$ & $6(2.2)$ & 0.02 \\
\hline Farmers, vets and gardeners & $30(43.5)$ & $51(18.4)$ & $<0.01$ \\
\hline Chemical industry & $2(2.9)$ & $0(0)$ & 0.04 \\
\hline
\end{tabular}

To have worked in a metallurgical and steel industry (OR 4.8 95\% CI 1.5-15.3) and to be a farmer, vet or gardener (OR 2.7 95\% CI 1.5-5.1) increased the risk of UIP (Table 2). There was an association between a longer occupational exposure in any job at risk of UIP and the risk of UIP (Table 3).

The self-reported exposure confirmed the findings obtained from the job title analysis underlying an excess of risk if the subject reported the exposure to metal dust and fumes or organic dust. In this latter analysis a self- reported exposure to environmental tobacco smoke doubled the risk of UIP (Table 4).

When the analysis was made considering also those who have reported shorter exposure $(<5$ years $)$ the results did not change (data not shown).

\section{Discussion}

The main finding of this study was the increased risk of UIP among those with a job known to be at risk of UIP. In detail, farmers, veterinarians, gardeners, metal and

Table 2 Job at risk for UIP in the whole sample, in men and women, adjusted for age and smoking

\begin{tabular}{llll}
\hline Exposure & All & Men & Women \\
\hline None & OR $(95 \% \mathrm{Cl})$ & $\mathrm{OR}(95 \% \mathrm{Cl})$ & $\mathrm{OR}(95 \% \mathrm{Cl})$ \\
Any job at risk of UIP & 1 & 1 & 1 \\
Costruction workers & $4.14(2.27-7.53)$ & $4.40(2.13-9.05)$ & $3.91(1.18-12.86)$ \\
Wood industry workers & $1.31(0.58-2.98)$ & $1.37(0.60-3.12)$ & - \\
Metallurgical and steel industry & $1.36(0.46-3.97)$ & $1.35(0.46-3.95)$ & - \\
Farmers, vets and gardeners & $4.80(1.50-15.33)$ & $4.76(1.50-15.15)$ & - \\
\hline
\end{tabular}


Table 3 Effect of the length of the occupation in a job at risk of UIP and the risk of UIP, adjusted for sex, age and smoking

\begin{tabular}{lll}
\hline Exposure & $\mathrm{OR}$ & $95 \% \mathrm{Cl}$ \\
\hline None & 1 & \\
$1-9$ years & 3.32 & $1.06-10.33$ \\
$10-19$ years & 3.41 & $1.30-8.95$ \\
$\geq 20$ years & 5.01 & $2.55-9.84$ \\
\hline
\end{tabular}

Significant risk estimates in italic

steel workers were at risk of UIP. Self-reported exposure to metal dust, fumes and organic dust was confirmed as a risk factor for UIP. This association provided support for the hypothesis that pulmonary fibrosis may be a heterogeneous disorder caused by a number of environmental and occupational exposures. The same risk factors have been found in observational studies from different countries [9]. Agricultural workers, veterinarians and gardeners are exposed to organic dust and aerosolized particulates from a variety of sources, including feed grains, bedding and cattle fecal material. The contribution of this exposure to the pathogenesis of lung fibrosis is not completely clear, but, even if all the cases were negative for common serum precipitins, the presence of end-stage unrecognized chronic hypersensitivity pneumonitis can not be excluded. In fact, chronic hypersensitivity pneumonitis could have an UIP radiological pattern [10] and can be confused with idiopathic pulmonary fibrosis, also by experienced physicians [11]. Moreover, veterinarians are usually less exposed to organic dust than agricultural workers and gardener, in this study the contribution of this job title (veterinarians) to the risk of UIP was quite low, since we had just one controls doing this job and his exclusion from the study did not change significantly the results.

The association between metal exposure and lung fibrosis is demonstrated in original studies [6] and review [12]. Metal-related lung fibrosis could be explained by the transition of alveolar cells to mesenchymal cells, caused by reactive oxygen species [13], where some metals are well established inducers of reactive oxygen species [14]. However, asbestos exposure in steel and

Table 4 Self-reported exposure and risk for UIP, adjusted for age, gender and smoking

\begin{tabular}{llll}
\hline Occupational exposure & $\begin{array}{l}\text { Cases } \\
\mathrm{n}\end{array}$ & $\begin{array}{l}\text { Controls } \\
\mathrm{n}\end{array}$ & $\mathrm{OR}(95 \% \mathrm{Cl})$ \\
\hline Metal Dust or metal fumes & 9 & 9 & $3.8(1.2-12.2)$ \\
Mineral Dust & 23 & 39 & $1.7(0.8-3.6)$ \\
Organic Dust & 37 & 104 & $2.4(1.3-4.3)$ \\
Vapours, gas, fumes & 25 & 85 & $0.9(0.5-1.7)$ \\
Environmental tobacco smoke at work & 43 & 116 & $2.2(1.2-4.0)$ \\
\hline
\end{tabular}

Significant risk estimates in italic metallurgy, as well in construction industry, can not be excluded [15], especially in those working in steel mills before ' 90 s.

In a previous similar study an association between severe pulmonary fibrosis and wood exposure was found; in this study wood dust exposure did not affect significantly the risk of IPF. This finding could be explained by the different geographical origins of the population considered, reflecting also different economic and productive situation and thus occupational exposures. As a matter of fact, in the present study, the number of subjects exposed to wood dust was rather low compared to the previous study [7].

The association with occupational exposure was timedependent: the risk of IPF increases with the duration of exposure. The finding of a dose-response relationship between years of potential exposure and risk of disease confirmed previous findings $[16,17]$. The exposure assessment in this study was not based only on selfreported exposure, easily prone to recall bias by IPF patients, but also on a job exposure matrix, grounded on previous studies merged in reviews. The reason to consider just reviews was to have a more homogeneous source of information. Anyway, to avoid misclassification, an a posteriori literature search among original articles was performed, confirming the same results obtained with reviews- restricted search. Anyway, we can not exclude exposure misclassification, beside the possibile asbestos exposure in steel and metallurgy, carpenters, classified as wood workers could have been also exposed to asbestos, as well many construction workers.

In this study, we do not perform matching and gender distribution was not similar among cases and controls. Nevertheless, stratified analysis for gender led to the same results in men and women (data not shown), even if women did not report to work or have worked in some occupations (construction, wood and metal).

In the International Consensus Statement regarding the diagnosis and treatment of IPF, Costabel et al. cited cigarette smoking as a potential risk factor for IPF [18] and it have shown in previous studies a dose-related association with increased risk of severe pulmonary fibrosis [19]. Our findings do not support this association, maybe because ever-smoking prevalence, despite the recent introduction of restrictions, is still rather high in Southern Europe, compared to other western countries from where the majority of previous studies were coming. The high prevalence of smokers could be one of the reason of a very high prevalence of self-reported exposure to environmental tobacco smoke in this study among UIP patients (62. $3 \%$ ), although a recall bias or same artifact in the statistical analysis cannot be excluded.

One of the strengths of the present study is the case definition, which includes cases with a medical diagnosis of UIP based on medical records with rather strict exclusion 
criteria, lung CT-scan UIP radiological pattern and, when available, histological data. In previous studies, case definition by medication registry (e.g. liquid oxygen therapy registry) could yield to misclassification and survivor bias [20]. Moreover, the recruitment of controls from the general population of the same catchment area should avoid bias related to the presence of shared risk factors (smoking, occupation) in an hospital-based case-control design. Not having imaging from control subjects could lead to a classification bias, if some of the controls has a not yet diagnosed pulmonary fibrosis; however, the very low prevalence of UIP in the general population (8.2 cases/100000) [21] could reduce the risk of this bias.

The reason to exclude exposure in the five years before the diagnosis is based on the nature of IPF which is chronic and progressive and a minimum lag time of five years was considered reasonable, based on previous studies dealing with occupational exposures to a known fibrogenic agent, such as silica, and the occurrence of non-malignant fibrotic lung diseases, such as silicosis [22]. However, in a case-control study design, the criterion of temporality, with exposure preceding the onset of UIP, cannot be established safely, because exposure and disease are measured, unlike cohort study, simultaneously [23] and UIP, as other chronic diseases, could also have been diagnosed later than the real onset.

A possible limitation of this study is the low number of cases, but other previous [23] and more recent studies, even if multicenter, have considered similar numbers [24].

Lack of matching for gender and age could be seen as another potential limitation, but the homogeneity of the sample, recruited in the same area and the results after adjustment for age and gender in the whole model and stratification for gender, could contribute to reduce the burden of this limitation on risk estimates. Moreover, it is not clear whether gender is a strong confounder (e.g. for hormone-related issues or for some protective effect of pregnancy on UIP) or an intermediate factor because the exposure to some occupational or environmental risk factor for UIP is more likely to occur in men. Therefore, to avoid underestimation, we decide to not match for gender.

Another possible drawback of a case-control design is the risk of recall bias regarding the exposure assessment. However, in this study, the use of a job exposure matrix would reduce significantly the risk of recall bias in cases and controls.

Another limitation, difficult to overcome given this study design, is the change in exposure intensity over years [25], it is plausible that younger participants underwent to a lighter exposure than the older ones. A larger number of cases could have allowed a stratified analysis for age, which could take into account this aspect.
Finally, some important risk factor for UIP, such as acid microaspiration in gastroesophageal reflux (GER), have not been taken into account in this study. However, GER have been found frequently in UIP patients but its role in causation is still rather unclear, furthermore, diagnostic tools to evaluate the occurrence of GER prior the diagnosis of UIP are still lacking [26].

\section{Conclusions}

Despite some potential limitations, this study confirm data from previous epidemiological studies and overall stress the importance of occupational and environmental factors in UIP pathogenesis. A better understanding of the risk factors for UIP is still needed to prevent its occurrence and, in order to assess the real impact of occupational exposure, further studies are required in larger population samples.

\section{Additional file}

Additional file 1: Flow chart showing the selection process of the literature used to highlight occupational exposures considered at risk of IP. (DOCX 68 kb)

\section{Abbreviations \\ GER: Gastro esophageal reflux; HRCT: High resolution CT-scan; IPF: Idiopathic pulmonary fibrosis; SLB: Surgical lung biopsy; UIP: Usual interstitial pneumonia \\ Funding \\ The Italian National Institute for Insurance against Accidents at Work (INAIL) supported the study.}

Availability of data and materials

The datasets used and/or analysed during the current study are available from the corresponding author on reasonable request.

\section{Authors' contributions}

GP contribute to plan the study, perform the survey, contribute to write the manuscript, contribute to data analysis; IF contribute to plan the study, contribute to write the manuscript, contribute to data analysis; KT contribute to plan the study, review the manuscript; ME contribute to plan the study, contribute to write the manuscript; MDO contribute to perform the survey, contribute to write the manuscript; GM contribute to recruit cases, review the manuscript; NM contribute to plan the study, contribute to recruit cases, contribute to data analysis, contribute to write and review the manuscript.

All authors have read and approved the manuscript.

Ethics approval and consent to participate

The study protocol was approved by the Regional Ethical Committee (CEAS UMBRIA) and all the participants gave their informed consent to the study and to the publication of the results.

Competing interests

All the authors declare that they have no competing interests about the subject and the content of this article.

\section{Publisher's Note}

Springer Nature remains neutral with regard to jurisdictional claims in published maps and institutional affiliations. 
Received: 24 May 2017 Accepted: 8 May 2018

Published online: 21 May 2018

\section{References}

1. Raghu G, Collard HR, Egan JJ, et al. An official ATS/ERS/JRS/ALAT statement: idiopathic pulmonary fibrosis: evidence -based guidelines for diagnosis and management. Am J Respir Crit Care Med. 2011;183:788-824.

2. An official American Thoracic Society/European Respiratory Society Statement. Update of the international multidisciplinary classification of the idiopathic interstitial pneumonias. Am J Respir Crit Care Med Sep. 2013;188: 733-48.

3. King TE Jr, Pardo A, Selman M. Idiopathic pulmonary fibrosis. Lancet. 2011; 378:1949-61.

4. Navaratnam V, Fleming KM, West J, et al. The rising incidence of idiopathic pulmonary fibrosis in the U.K. Thorax. 2011;66:462-7.

5. Macneal K, Schwartz DA. The genetc and environmental causes of pulmonary fibrosis. ProcAmThorac Soc. 2012;9:120-5.

6. Baumgartner KB, Samet JM, Coultas DB, et al. Occupational and environmental risk factors for idiopathic pulmonary fibrosis: a multicentre case-control study. Collaborating centers. Am J Epidemiol. 2000;152(4):307-15.

7. Gustafson T, Dahlman-Höglund A, Nilsson K, et al. Occupational exposure and severe pulmonary fibrosis. Respir Med. 2007;101(10):2207-12. Epub 2007 Jul 12

8. Awadalla NJ, Hegazy A, Elmetwally RA, et al. Occupational and environmental risk factors for idiopathic pulmonary fibrosis in Egypt: a multicenter case-control study. Int J Occup Environ Med. 2012;3(3):107-16.

9. Taskar VS, Coultas DB. Is idiopathic pulmonary fibrosis an environmental disease? Proc Am Thorac Soc. 2006;3(4):293-8.

10. Vasakova M, Morell F, Walsh $\mathrm{S}$, et al. Hypersensitivity pneumonitis: perspectives in diagnosis and management. Am J Respir Crit Care Med. 2017;196(6):680-9.

11. Morell F, Villar A, Montero MÁ, et al. Chronic hypersensitivity pneumonitis in patients diagnosed with idiopathic pulmonary fibrosis: a prospective casecohort study. Lancet Respir Med. 2013;1 (9):685-94.

12. Fontenot AP, Amicosante M. Metal-induced diffuse lung disease. Semin Respir Crit Care Med. 2008;29(6):662-9.

13. Wu CH, Tang SC, Wang PH, et al. Nickel-induced epithelial-mesenchymal transition by reactive oxygen species generation and $\mathrm{E}$-cadherin promoter hypermethylation. J Biol Chem. 2012;287(30):25292-302.

14. Barchowsky A, O'Hara KA. Metal-induced cell signaling and gene activation in lung diseases. Free Radic Biol Med. 2003;34(9):1130-5.

15. Nesti M, Marinaccio A, Gennaro V, et al. ReNaM working group. Epidemiologic surveillance for primary prevention of malignant mesothelioma: the Italian experience. Med Lav. 2005;96(4):338-46.

16. Hubbard R. Occupational dust exposure and the aetiology of cryptogenic fibrosing alveolitis. Eur Respir I Suppl. 2001;32:119s-21s.

17. Garantziotis S, Schwartz DA. Host-environment interactions in pulmonary fibrosis. Semin Respir Crit Care Med. 2006;27(6):574-80. Review

18. Costabel U, King TE. International consensus statement on idiopathic pulmonary fibrosis. Eur Respir J. 2001;17(2):163-7.

19. Coultas DB, Zumwalt RE, Black WC, et al. The epidemiology of interstitial lung diseases. Am J Respir Crit Care Med. 1994;150(4):967-72.

20. Ekström M, Gustafson T, Boman K, et al. Effects of smoking, gender and occupational exposure on the risk of severe pulmonary fibrosis: a population-based case-control study. BMJ Open. 2014;4(1):e004018. https:// doi.org/10.1136/bmjopen-2013-004018.

21. Duchemann B, Annesi-Maesano I, Jacobe de Naurois C, et al. Prevalence and incidence of interstitial lung diseases in a multi-ethnic county of greater Paris. Eur Respir J. 2017;50(2):1602419. [https://doi.org/10.1183/ 13993003.02419-2016].

22. Kreuzer M, Sogl M, Brüske I, et al. Silica dust, radon and death from nonmalignant respiratory diseases in German uranium miners. Occup Environ Med. 2013;70(12):869-75

23. Hubbard R, Cooper M, Antoniak M, et al. Risk of cryptogenic fibrosing alveolitis in metal workers. Lancet. 2000;355(9202):466-7.
24. Koo JW, Myong JP, Yoon HK, et al. Occupational exposure and idiopathic pulmonary fibrosis: a multicentre case-control study in Korea. Int J Tuberc Lung Dis. 2017;21 (1):107-12.

25. Peters $S$, Kromhout $H$, Portengen $L$, et al. Sensitivity analyses of exposure estimates from a quantitative job-exposure matrix (SYN-JEM) for use in community-based studies. Ann Occup Hyg. 2013;57(1):98-106.

26. Lee JS. The role of gastroesophageal reflux and microaspiration in idiopathic pulmonary fibrosis. Clin Pulm Med. 2014;21(2):81-5.

\section{Ready to submit your research? Choose BMC and benefit from:}

- fast, convenient online submission

- thorough peer review by experienced researchers in your field

- rapid publication on acceptance

- support for research data, including large and complex data types

- gold Open Access which fosters wider collaboration and increased citations

- maximum visibility for your research: over $100 \mathrm{M}$ website views per year

At BMC, research is always in progress.

Learn more biomedcentral.com/submissions 